\title{
Results of the multicentric management of infertility couples in Abidjan (Cote d'Ivoire)
}

\author{
Jean Marc Dia ${ }^{1 *}$, Telly $\mathrm{Sy}^{2}$, Eric Bohoussou${ }^{1}$, Mouhideen Oyeladé1, Gerard Okon ${ }^{1}$, \\ Privat Guié ${ }^{1}$, Simplice Anongba ${ }^{1}$
}

${ }^{1}$ Department of Obstetrics and Gynecology, CHU of Treichville, Côte d'Ivoire

${ }^{2}$ Department of Obstetrics and Gynecology, Maternity, Ignace Deen CHU de Conakry, Conakry, Guinée

Received: 16 February 2017

Accepted: 24 March 2017

\author{
*Correspondence: \\ Dr. Jean Marc Dia, \\ E-mail: jmlaminedia@yahoo.fr
}

Copyright: () the author(s), publisher and licensee Medip Academy. This is an open-access article distributed under the terms of the Creative Commons Attribution Non-Commercial License, which permits unrestricted non-commercial use, distribution, and reproduction in any medium, provided the original work is properly cited.

\begin{abstract}
Background: The management of infertile couples has seen many advances characterized today by the different techniques of medically assisted procreation (MAP) that are increasingly practiced in the developed countries. The objective of present study is to describe our experience of multicentric management of infertile couples in our ivorian context.

Methods: This is a retrospective and cohort study with descriptive purpose over 210 couples treated for infertility in the gynecology services of the University and Hospital Center of Treichville and a private clinic in Abidjan, from $1^{\text {st }}$ February 2013 to $31^{\text {st }}$ January 2017 (48 months).

Results: The frequency of infertility was $14 \%$, and the average age was 34.3 years for women and 43.2 years for men. The etiologies were found in 199 couples $(94.8 \%)$, particularly in 136 women and 113 men. The main causes were uterine $(58.1 \%)$, and hormonal $(26.5 \%)$ in women and of infectious origin in men $(79.7 \%)$. The majority of the patients (113 women and 97 men) received an etiologic treatment, dominated by myomectomia in women (67 patients) and targeted antiobitherapy in men (84.5\%). Moreover 113 couples (53.8\%) received a medically assisted procreation. After the management 110 couples (52.4\%) got pregnant.

Conclusions: The multicenter management has enabled infertile couples to have access to modern methods in their care.
\end{abstract}

Keywords: Etiologies, Infertility couple, Medically assisted procreation, Treatment

\section{INTRODUCTION}

The management of infertile couples has seen many advances characterized today by the different techniques of medically assisted procreation (MAP) that are increasingly practiced in the developed countries. But in our developing countries, where infertility affects 10 to $20 \%$ of couples, their management often raises problems related to the inadequacy of specialists and limited technical facilities. ${ }^{1}$ In Côte d'Ivoire, the first MAP centers are less than ten (10) years old and are mostly private establishments. Thus, couples followed for infertility in our public centers like the gynecology service of the University and Hospital Center of Treichville, are often oriented to private establishments to optimize their management. This work aims to describe our experience of the multicentric management of infertile couples in our ivorian context.

\section{METHODS}

This was a retrospective and cohort study with descriptive purpose conducted from $1^{\text {st }}$ February 2013 to 
$31^{\text {st }}$ January 2017 (48 months) on couples followed for infertility in the gynecology services of the University and Hospital Center of Treichville (CHUT) and a private clinic in our country (in Abidjan).

We included in the study all couples who, during the study period, were treated for infertility and monitored over the 2 years following the date of their authorization to contract a pregnancy. In the follow up of the patients, the pregnancy diagnosis was conducted on the basis of biological test or pelvic ultra sound.

The parameters studied were the epidemiological, etiological and therapeutic characteristics and the results of this management.

Data were collected on a survey sheet from patients records, follow-up sheets and telephone calls. The analyzes were carried out using the software EPI INFO version 2000, Word and Excel.

\section{RESULTS}

\section{Epidemiological characteristics}

\section{Frequency}

We recorded 2652 consultations during the study period including 372 cases of infertility an incidence of $14 \%$. Out of these 372 infertile couples, 210 met our inclusion criteria and were therefore selected for this study.

\section{Age of couples}

The average age of women was 34.3 years (extreme: 19 to 43 years) and among these, $73.3 \%$ were between 25 and 35 years of age.

In males, the average age was 43.2 years (extreme: 25 to 63 years) and the age group from 40 to 60 years was $89 \%$.

\section{Etiologies}

\section{Origin of the couple's infertility}

The cause of the infertility was found in 199 couples $(94.8 \%)$ and was of female origin in 86 couples $(41 \%)$, male in 63 couples $(30 \%)$, mixed in 50 couples $(23.8 \%)$ and unexplained in 11 couples $(5.2 \%)$. Thus, individually the cause of infertility was found in 136 women $(64.7 \%$ of women) and 113 men (53.8\% of men).

\section{Etiologies of female infertility}

The abnormalities found were of uterine origin in 79 patients $(58.1 \%)$, hormonal in 36 patients $(26.5 \%)$, and tubal in 26 patients $(19.1 \%)$.
Table 1: Distribution of women according to the causes of infertility.

\begin{tabular}{|lll|}
\hline Causes & Population & Frequency $(\%)$ \\
\hline Tuboperitoneal & 24 & 17.6 \\
\hline Uterines & & \\
\hline Fibroids & 51 & 37.5 \\
\hline Synechiae & 10 & 7.4 \\
\hline Polyps & 3 & 2.2 \\
\hline Endometriosis & 7 & 5.1 \\
\hline Hormonal & & \\
\hline Ovarian & 21 & 15.4 \\
\hline Hyperprolactinemia & 5 & 3.7 \\
\hline Mixed & 5 & 3.7 \\
\hline Multiples causes & & \\
\hline Uterines+tubal & 5 & 3.7 \\
\hline Uterines+Hormonal & 3 & 2.2 \\
\hline Tubal+Hormonal & 2 & 1.5 \\
\hline Total & $\mathbf{1 3 6}$ & $\mathbf{1 0 0}$ \\
\hline
\end{tabular}

\section{Etiologies of men infertility}

The main abnormalities found with spermograms were oligoasthenospermia (49.5\%), severe oligospermia (18.3\%) and azoospermia (8.8\%). The causes of these abnormalities were: infection in 90 patients (79.7\%), varicoceles in 14 patients $(12.4 \%)$, cryptorchidia in 5 patients $(4.4 \%)$, and hormonal disorders in 4 patients $(3.5 \%)$. Concerning the infectious causes, the main germs identified were Chlamydiae Trachomatis (41.6\%) and Ureoplasma (20.4\%).

\section{Treatment}

Treatment of women having an identified cause of infertility

Table 2: Distribution of women having an identified cause of infertility according to the type of treatment performed.

\begin{tabular}{|lll|}
\hline Type of treatment & Population & Frequency \\
\hline Etiological treatment & & \\
\hline Surgery & 83 & $61 \%$ \\
\hline Drug treatment & 26 & $19.1 \%$ \\
\hline Surgery+drug treatment & 4 & $2.9 \%$ \\
\hline MAP in 1st intention & 23 & $17 \%$ \\
\hline Total & $\mathbf{1 3 6}$ & $\mathbf{1 0 0 \%}$ \\
\hline
\end{tabular}

Type of treatment performed.

- Among 136 women having an identified cause of infertility, 113 patients $(83 \%)$ had an etiolical treatment, and 23 patients had MAP in first intention (17\%). The etiological drug treatments were conducted in isolated or associated ways. Thus Bromocriptin was used in $42 \%$ of women, and Progesteron in 58\%, Clomifen citrate in $28 \%$ and Gonadotrophin in $12 \%$. 
- As for the other types of treatment undertaken (Surgery and MAP), their modality was multiple according to the affection

Type of surgery performed in cause.

- Among the 113 patients who had an etiological treatment, surgery was performed in 87 patients (77\%), by endoscopy in 25 patients $(28.7 \%)$ and by laparotomia in 59 patients. During the surgery, myomectomia was performed in 67 patients $(87 \%)$.

Table 3: Distribution of patients according to the type of surgical treatment.

\begin{tabular}{|c|c|c|c|}
\hline Tracts & $\begin{array}{l}\text { Type of } \\
\text { surgery }\end{array}$ & Population & Frequency \\
\hline \multirow{3}{*}{ Laparoscopy } & $\begin{array}{l}\text { Tubal } \\
\text { Plastics }\end{array}$ & 5 & $5.7 \%$ \\
\hline & Myomectomy & 11 & $12.7 \%$ \\
\hline & Adhesiolysis & 2 & $2.3 \%$ \\
\hline \multirow{2}{*}{ Laparotomy } & Myomectomy & 56 & $64.5 \%$ \\
\hline & Cystectomy & 3 & $3.4 \%$ \\
\hline \multirow{2}{*}{ Hysteroscopy } & $\begin{array}{l}\text { Cure of } \\
\text { synechia }\end{array}$ & 4 & $4.6 \%$ \\
\hline & $\begin{array}{l}\text { Polyp } \\
\text { ablation }\end{array}$ & 3 & $3.4 \%$ \\
\hline $\begin{array}{l}\text { Classical } \\
\text { curettage }\end{array}$ & $\begin{array}{l}\text { Cure of } \\
\text { synechiae }\end{array}$ & 3 & $3.4 \%$ \\
\hline Total & & 87 & $100 \%$ \\
\hline
\end{tabular}

Treatment of men having an identified cause of infertility

The drug treatments undertaken were: antibiotic therapy (82 patients), bromocriptine (2 patients), and testosterone ( 2 patients). As for surgical treatments, they consisted of 11 varicocele cures.

Table 4: Distribution of men according to the type of treatment.

\begin{tabular}{|lll|}
\hline Type of Treatment & Population & Frequency \\
\hline Etiological treatment & & \\
\hline Surgical & 11 & $9.7 \%$ \\
\hline Drug treatment & 86 & $76.1 \%$ \\
\hline MAP in 1st intention & 16 & $14.2 \%$ \\
\hline Total & $\mathbf{1 1 3}$ & $\mathbf{1 0 0 \%}$ \\
\hline
\end{tabular}

Treatment of couples with unexplained infertility

All the 11 couples who had an unexplained infertility received an ovarian stimulation in $1^{\text {st }}$ Intention. Secondly 7 couples had a MAP in 2 nd intention.

The different types of MAP practiced in the couples

Finally, out of 210 couples treated, the MAP was practiced in 113 couples $(53.8 \%)$, and 97 couples had a classical treatment without MAP (46.2).
Table 5: Distribution of couples according to the type of MAP carried out.

\begin{tabular}{|lll|}
\hline $\begin{array}{l}\text { Type of MAP in the } \\
\text { couple }\end{array}$ & $\begin{array}{l}\text { Population } \\
\text { In 1 }\end{array}$ & $\begin{array}{l}\text { Frequency } \\
(\%)\end{array}$ \\
\hline $\begin{array}{ll}\text { Stimulation of ovulation } \\
\text { Insemination }\end{array}$ & 12 & 29.3 \\
\hline IVF & 9 & 22.0 \\
\hline Total & 20 & 48.7 \\
\hline In 2 nd intention & 41 & 100 \\
\hline Stimulation of ovulation & 4 & \\
\hline Insemination & 6 & 4.5 \\
\hline IVF & 78 & 6.8 \\
\hline Total & $\mathbf{8 8}$ & 88.7 \\
\hline
\end{tabular}

Concerning the MAP, the insemination was practiced in 15 couples $(13.3 \%)$ and IVF in 98 couples $(86.7 \%)$. These IVF were performed classically in 66 couples $(67.3 \%)$ and with ICSI in 32 patients $(32.7 \%)$. Furthermore, during the MAP, 49 couples (43.4\%) benefited from donation of gamete.

\section{Outcome of treatment}

After different treatments of the 210 couples, 110 couples got pregnant $(52.4 \%)$ including 67 after classical treatment and 43 after a MAP (38.1\% of the couples who had a MAP).

\section{DISCUSSION}

\section{Epidemiological characteristics}

\section{Frequency of infertility}

The frequency of infertility in our series was $14 \%$. It was close to those found by various authors in Africa an in developed countries 10 to $20 \% .^{1-3}$ This finding reflects the extent of infertility in our developing countries often masked by rapid population growth.

\section{The age of the women}

The average age was 34.3 years (extreme 19-43 years) closer to those found by Boudhraa in Tusnisia (33.3 years) and Bang in Gabon (34.9 years). ${ }^{4,5}$ Furthermore, the majority of our patients were aged between 25 and 35 years $(73.3 \%)$, being thus in the ideal time to resolve their infertility problem because beyond this time we enter periods of pregnancy in older women. Indeed, pregnancy after 35 years become scarce and more exposed to complications. . $^{2,6,7}$

\section{The age of men}

Men can be fertile from puberty until 90 years, even 100 years. ${ }^{8}$ The age of men in our population was not a real obstacle to their fertility because $89 \%$ of the spouses 
were between 40 and 60 years of age (extreme 25-63 years). Nevertheless, it was important to solve the infertility problems of these patients at an age when they still have all their vigor to properly care for their offspring.

\section{Causes of infertility}

\section{Causes of infertility in women}

Etiologies of infertility in our population was dominated by uterine abnormalities ( $58.1 \%)$, mainly fibroids. Gandji also found uterine factors as the leading cause of infertility in women in his study. ${ }^{9}$ In addition, fibroids are known for their high frequency among black women. ${ }^{9,10}$ They become a source of infertility depending on their location and size. In our poor countries without social security, it is still common to encounter patients with voluminous fibroids known as historical.

Finally, in our series, hormonal abnormalities (26.5\%) and tubal $(19.1 \%)$ were also major causes of infertility after the fibroids.

\section{Causes of infertility in men}

The abnormalities of the spermogram were dominated by oligoasthenospermia in our population $(49.5 \%)$, with the main causes being infections $(79.7 \%)$ to Chlamydiae trachomatis $(41.6 \%)$.

Several authors have also observed the predominance of oligoasthenospermia in spermogram disorders, and infection in the causes of male infertility. ${ }^{11-14}$ Chlamydia trachomatis infection in particular have the distinction of being asymptomatic with consequences on fertility, even in a frozen sperm. ${ }^{14}$

Also in our study, many non-infectious causes of infertility were found $(20.3 \%)$. They were mainly due to varicocele $(12.4 \%)$, cryptorchidism $(4.4 \%)$ and hormonal disorders $(3.5 \%)$. These non-infectious causes are often described in the literature and Audebert reported in his series a high rate of varicocele $(29 \%)$ in the causes of male infertility. ${ }^{15,16}$ These pathologies occur mostly in the childhood of patients, justifying a prenuptial assessment before any life of couple where the partners intend to make a child.

\section{Treatment characteristics}

\section{Etiological treatment in women}

The etiological management of female infertility in our population was essentially surgical (77\%). And myomectomies were the most frequently used (77\%), mostly by laparotomy $(64.5 \%)$. The predominance of laparotomy in myomectomies in our context can be explained for two reasons: patients often consult late in stages where laparoscopy no longer has a place, and the scarcity of structures with laparoscopic columns.

Nevertheless, endoscopic surgery was performed in some of our patients $(28.7 \%)$. These endoscopic surgeries were all carried out in the private structure of our study, since the CHUT does not have an endoscopic column. This collaboration between the public and private sectors allows our patients to benefit from modern methods in their care. As for drug treatments, we used hormone therapy in the majority of cases, conducted in isolation or association according to the objectives.

\section{Etiological treatment in men}

The majority of men in our series were treated with medication (76.1\%), particularly targeted antibiotic therapy (82 patients). However, surgery was performed in 11 men for varicocele cures. The surgical treatment of mechanical obstacles in the treatment of male infertility has often been reported in Africa. ${ }^{12,17}$

\section{Treatment of couples by MAP}

In our series, the majority of couples $(53.8 \%)$ received a MAP either in $1 \mathrm{sr}$ intention (29 couples), or in 2 nd intention after failure of a first etiological treatment $(84$ patients). The different MAP techniques were used in the private structure: inseminations (15 couples), IVF (98 couples), gametes donations (49 couples). In our country, the practice of the MAP is recent, dating less than 10 years, and is done in private institutions. Similarly, in Africa, various publications have reported the recent practice of MAP in some countries, which also takes place in private centers in general. ${ }^{12,17}$

\section{Outcome of treatment}

After the various treatments, a pregnancy occurred in the majority of the couples of our series $(52.4 \%)$. The success rates after MAP were $38.1 \%$ overall. Several infertility specialists from the third world have reported encouraging rates of pregnancy after infertility treatment of the couple. N'Doye in Senegal and Bouchra in Morocco, reported 20 to $24 \%$ of pregnancy after management of the infertility of the couple by MAP. ${ }^{18,19}$ In developed countries with much more experience in MAP practice, success rates are relatively higher: $46 \%$ to $48 \% .^{8}$

\section{CONCLUSION}

This study showed that couple infertility was common in our context. The multicentric approach allowed a modern and optimal management of ours couples. Thus, the MAP techniques were performed in the majority of patients leading to satisfactory success rates.

Funding: No funding sources Conflict of interest: None declared 
Ethical approval: The study was approved by the Institutional Ethics Committee

\section{REFERENCES}

1. Larsen U. Primary and secondary infertility in SubSaharan Africa. Int J Epidemiol. 2000;29:285-9.

2. Blumenthal LJ, Hertzanou F, Mendelsohn DB, Golgdberger S. Epidemiology of infertility. S Africa Johannesburg Med. 1984;21:854-6.

3. Boivin J, Bunting L, Collins JA, Nygren KG. International estimates of infertility prevalence and treatment-seeking: potential need and demand for infertility medical care. Hum Reprod. 2007;22(6):1506-12.

4. Boudhraa K, Jellouli MA, Kassaoui O, Ben Aissia N, Ouerhani R, Triki A, et al. Interest of hysteroscopy and laparoscopy in the management of infertile coulpe: about 200 cases. Tunis Med. 2009;87(1):5560.

5. Bang Ntamack JA, Mayi-Tsonga S, Sima Ole B, Meye JF. Pregnancy after myomectomy in Libreville, Gabon. Clin Mother Child Health. 2009;6(2):1101-6.

6. Miller DA. Is advanced maternal age an independent risk factor for uteroplacental insufficiency? Am J Obst Gynecol. 2005;192(6):1974-80.

7. Martin A, Maillet R. Pregnancy after 40 years. Excerpt from Updates in Gynecol Obstet. 2005;29:65-92.

8. Adamson GD; Baker VL. Sub fertility: causes; treatment and outcome. Best Pract Res Clin Obst Gynecol. 2003;17(2):169-85.

9. Gandji S, Adisso S, Atrevi N, Dougnon TV, Bankolé HS, Hontonnou F, et al. Diagnosis of the etiological lesions of secondary infertility in Cotonou: role of hysterosalpingography and pelvic ultrasound. J Appl Biosci. 2013;68:5349-55.

10. Zeghal D, Ayachi A, Mahjoub S, Boulahya G, Zakraoui A, Ben Hmid R, et al. Fibrome et grossesse: les complications. La Tunisie Medicale. 2012;90:286-90.
11. Niang L, Ndoye M, Labou I, Jalloh M, Kane R, Diaw JJ, et al. Epidemiological and clinical profile of male infertility in the general hospital of Grand-Yoff, Senegal: about 492 cases. Andrologie. 2009;19:1037.

12. Moreira P, Fall C, Dieng T, Fall A, Diouf A, Moreau JC. Medically assisted procreation: indications and perceptions by couples with infertility at the Dakar University Hospital Center. Mali Med. 2008;23(1):50-6.

13. Ayaud O, Bijaoui G, Huynh B. Genital Bacterial Infections Associated with Papillomavirus: Screening and Treatment Basis, Contraception. Fertil Sex. 1993;21:149-52.

14. Mieusset R. Cell-tropic germs (Chlamydiae, Mycoplasma) and disturbance of sperm fertility. Andrologie, 1994;4:406-13.

15. Darcq C, Hermabessiere J. Etiology of secondary infertility in man. Androl. 2006;16(2):155-9.

16. Audebert A. Varicocele and male hypofertility: current data. Obst Gynecol. 1993;1(5):487-9.

17. Khallouk A, Tazi MF, EL Fassi MJ, Farib MH. Male infertility: pathophysiology, assessment and management. Esperance Médicale. 2010;17(170):421- 9 .

18. Ndoye M, Niang L, Labou I, Jalloh M, Kane R, Ndiaye JJDA, et al. Azoospermie in Senegal: what kind of care is available in ICSI? Androl. 2008;18(3):206-9.

19. Ouaggag B. La procreation medicalement assistee experience du secteur prive de marrakech. Universite cadi ayyad Faculty of Medicine and Pharmacy marrakech Thèse $\mathrm{N}^{\circ} 66$ soutenue publiquement en; 2007.

Cite this article as: Dia JM, Sy T, Bohoussou E, Oyeladé M, Okon G, Guié P, et al. Results of the multicentric management of infertility couples in Abidjan (Cote d'Ivoire). Int J Reprod Contracept Obstet Gynecol 2017;6:1753-7. 